\section{A Process-control Approach to Poinsettia Height Control}

\author{
Paul R. Fisher and \\ Royal D. Heins
}

Additional index words. technology transfer, knowledge-based system, control chart, graphical tracking, process control, Euphorbia pulcherrima, greenhouse

Summary. A methodology based on process-control approaches used in industrial production is introduced to control the height of poinsettia ( $E u$ phorbia pulcherrima L.). Graphical control charts of actual vs. target process data are intuitive and easy to use, rapidly identify trends, and provide a guideline to growers. Target reference values in the poinsettia height control chart accommodate the biological and industrial constraints of a stemelongation model and market specifications, respectively. A control algorithm (proportional-derivative control) provides a link between the control chart and a knowledge-based or expert computer system. A knowledge-based system can be used to encapsulate research information and production expertise and provide management recommendations to growers.

$\mathrm{T}$ he widespread use of computers for environmental control and monitoring in greenhouses provides an opportunity to implement model-based process control to manipulate temperature, humidity, $\mathrm{CO}_{2}$ concentration, nutrients, and pesticide inputs. In this type of control system, environmental variables are modified in real time based on plant requirements rather than rigid calendar timetables (e.g., Fynn et al., 1989; Jones et al., 1988 ). Several tasks are common to model-based control problems,

Department of Horticulture, Michigan State University, East Lansing, MI 48824-132.5

The cost of publishing this paper was defrayed in part by the payment of page charges. Under postal regulations, this paper therefore must be hereby marked advertise ment solely to indicate this fact. including defining production targets, monitoring production variables, identifying deviations from the desired performance, optimizing corrective actions, and implementing system changes.

In process control, actual and target performance levels can be compared over time in a graphical control chart (Ewan, 1963). For example, the measured diameter of an industrial component can be charted against the allowed minimum and maximum size to provide the decisionmaker with immediate performance feedback in an intuitive visual format. A control algorithm, generally referred to as proportional-integrative-derivative (PID) feedback control (Murrill, 1981), can be used to quantify trends in observed deviations in terms of a control index (CI). The CI represents the change in the system needed to return the observed performance to the desired level; for example, to raise or lower temperature in a thermostat system. Knowledge-based or expert systems (Stock, 1987) that capture qualitative expert knowledge in a computer program can interpret the control chart (Cook et al., 1992) and CI to suggest remedial action.

A decision area that lends itself to a process-control approach is height control of flowering potted plants such as poinsettia. Incorrect height-control decisions can reduce the market value of a flowering potted plant for aesthetic and economic reasons: consumers pay less for leggy and undersized plants, overly tall plants are more expensive to ship, and contract orders for poinsettia crops usually specify an acceptable height range for the finished plant. The inherent challenge is to produce a crop to specified market height limits without adversely affecting scheduling, quality, and profitability.

In this article, a novel use of process control is described to control the height of a poinsettia crop. Processcontrol approaches (control chart and PID control) are discussed in the first part of the article and then are applied to poinsettia height control. The implementation of these process-control approaches in a poinsettia grower's decision-support tool-The Greenhouse CARE System-is discussed in terms of its three main components: developing a graphical control chart, characterize. ing and interpreting the graph, and providing management recommendations on the basis of the analysis. 


\section{Modeling approach}

Control charts provide useful and easily understood diagnostic tools (Ewan, 1963; Miller, 1985). In a control chart (Fig. 1), a reference value is established as the desired average level of a controlled variable (Ewan, 1963). When the measured value of the controlled variable remains close to the reference, i.e., inside action limits, the system is in Control. Determination of action limits can be based on statistical or industrial criteria. Based on the magnitude and frequency of deviations from the desired mean, actions are taken to modify actual performance. However, a control chart plot alone does not demonstrate why a certain trend exists or what corrective actions should be taken (Miller, 1985).

Knowledge-based technology has been used to identify and interpret out-of-control situations on a control chart (Cook et al., 1992) in a quality control application for plywood manufacturing. A statistical control chart was developed, and eight antecedentconsequent (if.. then) rules based on statistical probability (Nelson, 1985 ) were used to identify when sufficient data points were above or below the reference value to identify a trend. For example, if six consecutive data points were increasing or decreasing, then the mill operator was alerted to a significant production trend. Another module in the plywood application used additional rules to provide management recommendations after a deviation occurred.

An alternative to heuristic interpretation of control charts is a PID control algorithm, which is used widely in the design of self-regulating control processes (Murrill 1981) and can be linked to a 'control chart to quantify deviations from the target value. In the case of thermostat-regulated temperature control, deviations of the controlled variable (temperature) from a desired setpoint are monitored, and a representation of a PID control algorithm in the thermostat is used to correct the error by changing a manipulated variable (fuel supply to the boiler). Three components of error that relate to the deviation of the controlled variable from the setpoint are defined in PID control. The proportional component is the absolute deviation $e(t)$ of the measured value $x(t)$ from the setpoint $s(t)$ at time $t$, where

$$
e(t)=s(t)-x(t)
$$

The integral component $e(t) d t$ is the sum of errors over a defined period of time, which represents the longerterm trend in error. The derivative component de/dt represents the rate of change in deviation (the deviation rate) toward or away from the setpoint.

The basic equation used to calculate the $\mathrm{CI}$, a value that causes a change in the controller, can be represented by

$C I=K_{c} e(t)+K_{i} e(t) d t+K_{d}(d e / d t)$

where $K_{c}, K_{i}$ and $K_{d}$ are constants assigned to each error component to stimulate the desired response from the controller (Quinn-Curtis, 1990). Murrill (1981) and Quinn-Curtis (1990) compared characteristics of control systems with various combinations of $K_{c}, K_{i r}$ and $K_{d}$ components. A high $K_{c}$ term leads to a rapid response proportional to the current deviation. Proportional control alone is simple and easy to tune, but is not sensitive to trends in process disturbances over time. Integral control is capable of tracking disturbances, and the integral term is proportional to the sum of previous process errors in the system. A high $K_{i}$ term is therefore affected more by long-term trends than the current deviation, and continues to add to the controller output until the sum of previous errors equals zero. The derivative component anticipates the error, providing a larger control

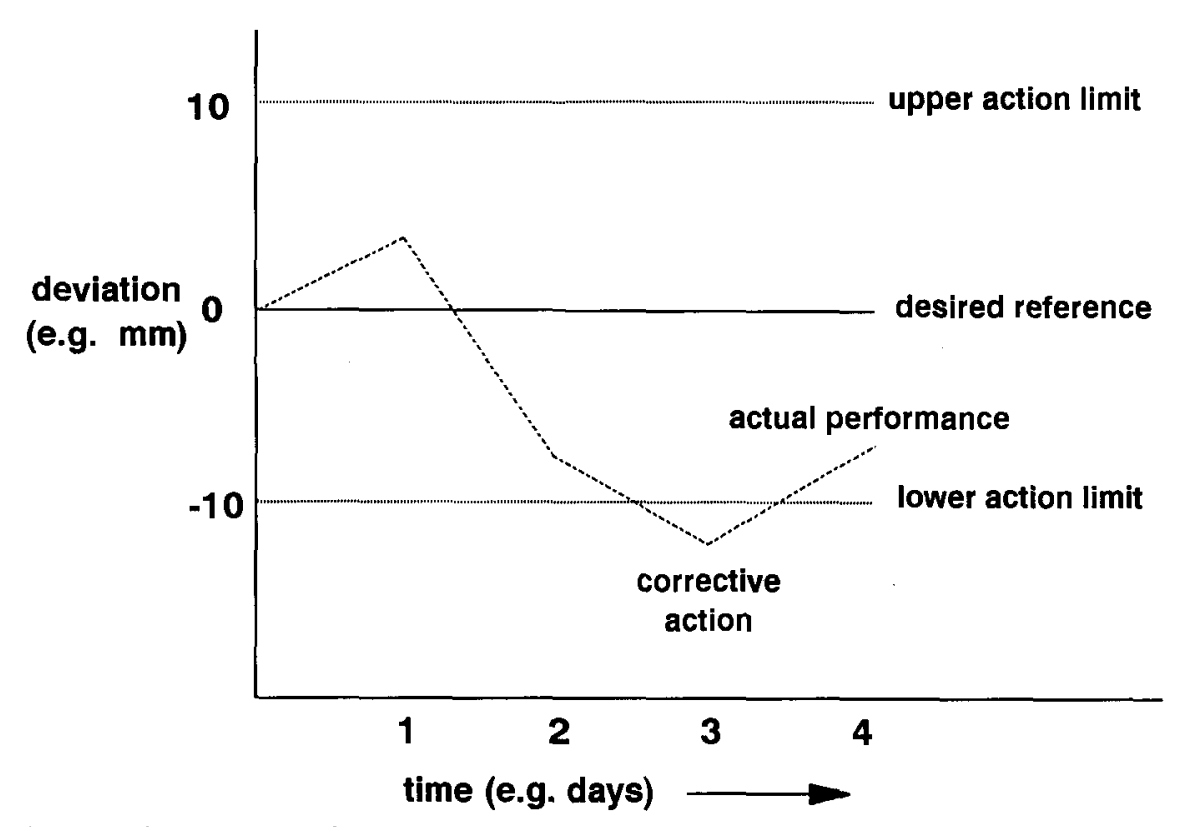

Fig. 1. Basic components of a control chart. response when the error term is going in the wrong direction (away from the reference) and a dampening response when the error term is going in the right direction.

If control actions are continuous, Eq. [2] can be used without modification to change the manipulated variable.However, in agricultural processes, the decision is often a mix of discrete and continuous options; for example, whether to apply a pesticide and at what rate. Where discrete management options are used, CI in Eq. [2] can be rounded to an integer value and each CI value can be described qualitatively based on potential management actions. For example, a CI of 0 can indicate that the system is under control; 1 , that a slight decrease in the controlled process variable is required; and +3 , that it is imperative to increase the controlled process variable. The CI therefore includes a direction (the sign) and magnitude (the absolute value) of required control actions.

A control situation can be defined further by dividing the production season into a series of decision stages within which recommendations do not vary as a function of time. Beck et al. (1989) described an approach used in the development of a knowledge-based system for soybean insect control, where decision stages were identified as a result of interviews with a domain expert (Stock, 1987), but, more important, on the basis of expert responses to problem scenarios. The boundaries for each stage were defined 


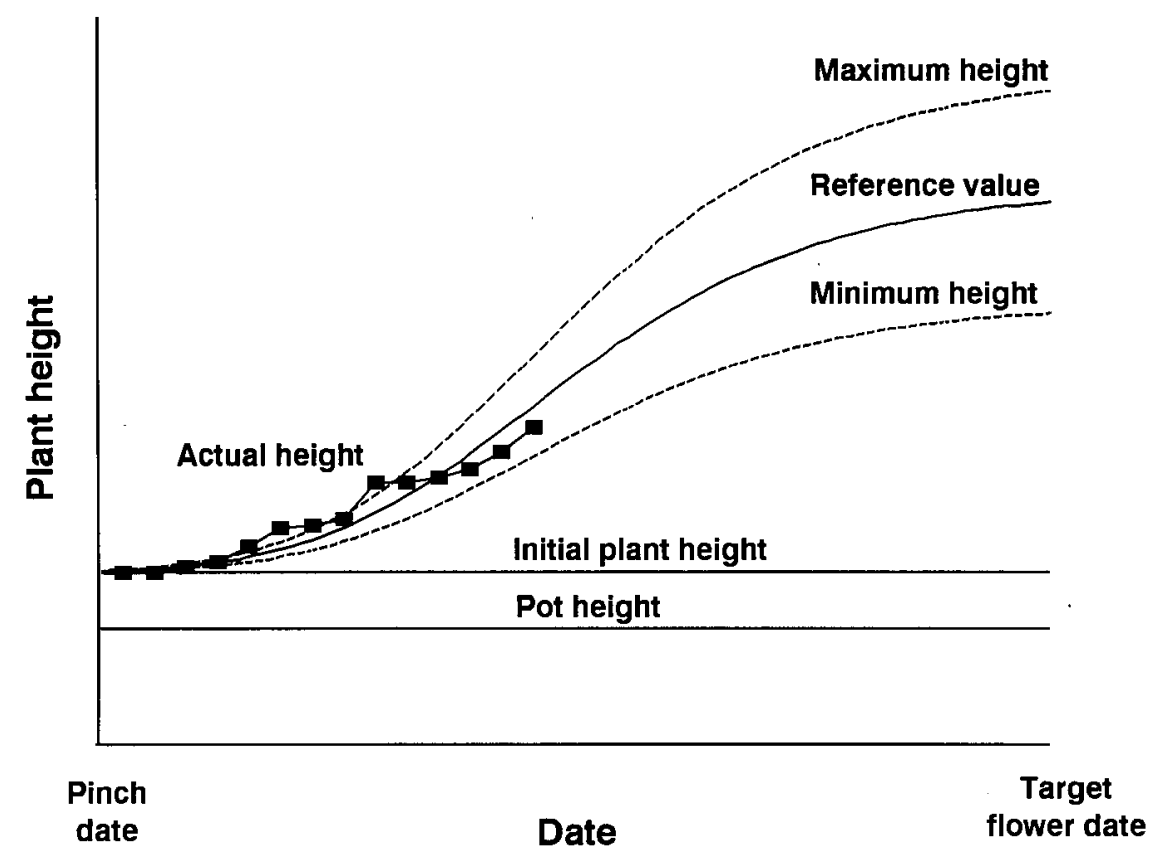

Fig. 2. Components of a graphical control chart for poinsettia height control.

by Beck et al. ( 1989) in production rules based on easily observable plant phonological events; for example, senescence or harvest.

An infinite number of possible control situations can therefore be characterized into a discrete number of scenarios. If viewed as a matrix (or action table) with the decision stage in the $\mathrm{x}$ axis and $\mathrm{CI}$ in the $\mathrm{y}$ axis, expert recommendations for each cell can be elucidated by interview techniques. By computing the CI and locating the relevant cell, the resulting recommendation can mimic that of Heins.

\section{Application to poinsettia height control}

Development of the graphical control chart. The graphical control curve for poinsettia height control was based on a sigmoid stem elongation model for pinched poinsettia (Berghage and Heins, 1991). Pinching refers to the manual removal of the stem apex to promote lateral branching. The dynamic internode-based model from Berghage and Heins (1991) was run with assumptions of constant $21 \mathrm{C}$ day and night temperature, and flower-inducing photoperiods beginning 25 days after pinch. The resulting model shoot length data then were converted to relative time and relative height by scaling both axes from 0 to 1 . The Richards function (Richards,1959),

$H=H\left[1+\exp \left(H_{0}-k t\right)\right]^{-1 / n}$ then was fit to the resulting normalized data. Parameter estimates for $H_{o}, H_{f} n$, and $k$ were $0.0131,1.018,0.3923$, and 5.8138 , respectively, and the $R^{2}$ was 0.99. To develop a control chart for a particular crop, the time axes were scaled from pinch to flower dates. Market contracts for poinsettia usually specify an acceptable range in final plant height, and the height axes were scaled to the minimum, maximum, and average final height specifications (Fig. 2).

The shape of the process control curve corresponds with physiological development of the crop. Immediately after the plant is pinched, there is a lag in stem elongation rate as lateral shoots begin development from dormant axillary buds. Stem elongation rate is approximately linear as new leaves unfold and internodes elongate until the terminal flower buds are visible. Several weeks after flower initiation, the bracts of the poinsettia begin to develop the final color (red, pink, or white) at a developmental stage generally called first color. Bracts expand over the next month, and large bracts are a desirable market feature. During the period of bract expansion, stem elongation rate slows to a plateau as the plant approaches flowering. Final plant height, determined by the length of side shoots, is a function of the number of leaves on a shoot and the length of internodes between leaves.

Using the graphical control chart for height control-graphical tracking-has been adopted widely by poin - settia, chrysanthemum, and Easter lily growers (Carlson and Heins, 1990). Growers either generate their own graphical control chart from published instructions ( Carlson and Heins, 1990) or are sent a facsimile of customized graphs from Michigan State Univ. Growers measure plant height with a ruler twice each week and plot the measurement on the graphical control chart (Fig. 2). Actual and reference heights are compared. If actual plant height is above the upper action limit, the crop is too tall, and action should be taken to decrease stem elongation rate (e. g., applying a growth retardant); conversely, stem-elongation rate should be increased if the height is below the target window height.

\section{The action table}

Paul Fisher was the knowledge engineer (Stock, 1987) in this project and Royal Heins was the primary source of expertise. Heins developed the graphical height control technique, has regularly advised growers about poinsettia production, and has conducted considerable research related to height control techniques (Berghage and Heins, 1991; Carlson and Heins, 1990; Erwin and Heins, 1990; Erwin et al., 1989; Heins and Erwin, 1990).

Following interviews, we defined five decision stages for poinsettia height control: (Stage 1) early growth until 1 week before first bract color, (Stage 2) the week before first bract color, (Stage 3) the first week of bract color, (Stage 4) the period of bract expansion, and (Stage 5) the 10 days before flowering. Optimum temperatures (Berghage and Heins, 1991) and the desirability of applying a growth retardant (Barrett and Nell, 1993 ) varied with stage of development and, within each decision stage, recommendations with respect to temperature and growth retardants were based on consistent criteria. The phonological events that delimited the decision stages could be observed readily by a grower or, for the start of Stage 2, could be predicted based on flower initiation date.

The range of possible recommendations within each decision stage then was structured in an action table (Table 1), a two-dimensional matrix that encapsulated growth retardant and temperature recommendations in an 8point CI. For reasons of brevity, only growth retardant recommendations are presented; however, each cell in the 
action table also contains a specific day and night temperature setpoint recommendation. In the CI approach, a value of -3 represented a strong need to reduce current stem elongation rate, a value of $\mathrm{O}$ meant current elongation rate could be maintained, and a value of 4 represented a strong need to promote stem elongation. Forty possible control scenarios were therefore defined: five decision stages times eight CI values.

Growth retardants reduce stem elongation rate primarily by interfering with gibberellin biosynthesis (Grossman, 1992) and are most useful during vegetative and early development of poinsettia because later applications reduce bract size (Barrett and Nell, 1993). The recommended rate or number of growth retardant applications (Table 1) increased with more negative CIS during the early growth stages. When the CI was 0 , a growth retardant was not recommended. During growth stages 2 to 4 , the action table warned that growth retardant applications may reduce bract size and/or delay flowering. Near the market date, no retardants were recommended because there was little potential for further stem elongation, and growth retardants were unlikely to be effective.

Estimating the CI. We used the PID algorithm to mimic Heins' interpretation of the control chart. An initial heuristic approach, in which rules were used to defined how concerned Heins was with particular scenarios, was discarded because the number of rules rapidly increased and were difficult to verify for completeness. Equation [2] was modified so that the CI was rounded to the nearest integer and limited to -3 and +4 . Because of infrequent measurements (once every 3 days), we -wanted the system to respond rapidly to deviations from the reference height; therefore, the integral constant $K_{i}$, which affects the lag in control response, was set to 0 . These changes modified Eq. [2],

$$
\begin{gathered}
C I=\operatorname{round}\left(K_{c} e(t)+K_{d}(d e / d t)\right. \\
-3 \leq C I \leq 4
\end{gathered}
$$

where time $t$ was measured in days, the error $\mathrm{e}(\mathrm{t})$ was measured in $\mathrm{cm}$, $\mathrm{de} / \mathrm{dt}$ was in $\mathrm{cm} /$ day, $K C$ had units of $\mathrm{cm}^{-}{ }^{1}$, and $K_{d}$ was $\mathrm{cm} /$ day.

Heins was presented with a random selection of height and stem elongation rate combinations at the five decision stages and identified which $\mathrm{CI}$ in the action table best matched his recommendation. Linear regression then was used to estimate $K_{c}$ and $K_{d}$ by using the CI values estimated by Heins as the dependent variable, and plant height and elongation rate as the independent variables. Results of the linear regression to estimate $K_{c}$ and $K_{d}$ (Table 2) indicated that Eq. [4] adequately represented Heins' choice of CI. An example control chart (Fig. 3a) shows how Eq. [4] was used. Actual heights for 14 and 17 Sept. were 19.3 and 21.4 $\mathrm{cm}$, respectively, and reference heights were 17.7 and $18.2 \mathrm{~cm}$. The CI for 17 Sept. was calculated as:

$$
\begin{aligned}
C I \quad & =\operatorname{round}(-0.51(21.4-18.2) \\
& -2.84((21.4-18.2)-(19.3 \\
& -17.7)) / 3) \\
& =\operatorname{round}(-1.63-1.51) \\
& =\operatorname{round}(-3.14) \\
& =-3 .
\end{aligned}
$$

Control recommendations. The knowledge-based system is composed of 125 "if.. then... " antecedent-consequent rules that are used to develop text recommendations in a brief report. The first task in the knowledge-based system is to identify the growth stage and calculate the CI. For example,
IF Current date $>$ first color date $+7$

AND Current date $<$ flower date -10

THEN Growth stage $=4$. Bract expansion

Rules then copy text into a section of the report that describes the current situation (growth stage and CI) to the user. For example, one rule states

IF $\quad \mathrm{CI}=-1$

AND Actual height $>$ the target height

THEN Copy to the report The crop is taller than desired, and steps should be taken to reduces stem elongation rate.

The next part of the report deals with whether a growth retardant should be applied and, if so, what chemical type, application method, and concentration. Each cell in the action table is represented as a rule, and rules are similar to, but more-detailed than the cells in Table 1. By looking up the appropriate rule (action table cell), the growth retardant recommendation is obtained; for example

IF Growth stage $=1$. Early

AND CI $=-2$

THEN Apply a growth retardant = yes

AND Concentration $=$ medium rate AND Appropriate chemicals = chlormequat, daminozidechlormequat mix, and ancymidol

In exceptional situations in which the elongation potential of the cultivar or the history of growth retardant applications apply, the basic action-table recommendations are modified by additional rules. For example, one rule avoids recommending growth retardants to short-growing cultivars in the first 2 weeks after pinch, even if crop height is above the target window:

IF The $\mathrm{CI}<=0$

AND The growth stage $=1$. Early

\begin{tabular}{|c|c|c|c|c|c|}
\hline \multirow{2}{*}{$\begin{array}{l}\text { Control } \\
\text { index } \\
\end{array}$} & \multicolumn{5}{|c|}{ Growth retardant recommendations during growth stage } \\
\hline & 1. Early & 2. Near first color & 3. First color & 4. Bract expansion & 5. Near market \\
\hline-3 & Medium rate ${ }^{z}$, repeat ${ }^{y}$ & 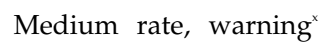 & Low rate, warning & No, warning & No, little effect \\
\hline-2 & Medium rate & Medium rate, warning & Low rate, warning & No, warning & No, little effect \\
\hline-1 & Low rate & Low rate, warning & No, warning & No, warning & No, little effect \\
\hline $0-4$ & No, not needed & No, not needed & No, not needed & No, not needed & No, not needed \\
\hline
\end{tabular}

AND Current date $<$ pinch date + 14

AND The cultivar = short-growing

THEN Apply a growth retardant = no

AND Copy to the report Although

Table 1. Simplified action table for growth retardant applications to poinsettia crops.

'Low- and medium-rate growth retardant applications were defined as 800 and 1500 ppm chlormcequat foliar sprays, respectively.

${ }^{r} \mathrm{~A}$ second (repeat) medium-rate application is recommended in this case, rather than a high rate application.

${ }^{x} \mathrm{~A}$ warning refers to thelikelihood of reduced bract size or delayed flowering if growth retardants are applied. 
Table 2. Estimates of $K_{c}$ and $K_{d} P I D$ parameters using regression analysis.

\begin{tabular}{lc} 
Parameter & Estimate $\pm 95 \%$ confidence limits \\
\hline $\mathrm{KC}$ & $-0.51 \pm 0.03 \mathrm{~cm}-1$ \\
$\mathrm{~K}_{\mathrm{d}}$ & $-2.84 \pm 0.18 \mathrm{~cm} /$ day \\
Observations (no. ) & 104 \\
$r^{2}$ & 0.85 \\
\hline
\end{tabular}

plant height is above the target window, do not apply a growth retardant at this stage. This cultivar tends to be slow-growing and the situation is not yet a problem.

The consequent parts of many rules, including the one above, contain text recommendations that are copied to the report. An example growth retardant recommendation based on the crop's being in growth stage 1 with a CI of -3 (17 Sept. in Fig. 3a) reads:

Apply a medium-rate, growth retardant. A second application may be required in 3-4 days. Consider one of the following. rates:

ancymidol drench : 0.25-0.50 mg/ 15$\mathrm{Cm}$ pot

daminozide/ chlormequat spray: 1000 ppm each

chlormequat spray: 1500 ppm chlormequat drench: 1500 ppm

\section{Implementation}

Working closely with a beta-test group of eight Michigan poinsettia producers, we incorporated the graphical control chart, PD algorithm, and knowledge-based system into an overall program. All were innovative growers, but their operations differed in scale, technical sophistication, and computer usage.. All but one were experienced with poinsettia production. Between 1990 and 1993, growers were visited regularly and sent program updates. More than 2 million plants were grown with the support of the program during this period. The program was refined based on other industry sources, greenhouse experiments, comments from the eight poinsettia producers, and comparison between the knowledge-based system and grower actions. Initial versions of the program combined an expert system shell, which is a programming language written specifically for developing knowledge-based systems (Stock, 1987), and a spreadsheet. The knowledge-based system primarily relied on a forward-chaining inference procedure (Stock, 1987), where all data needed to make a recommendation were stored in a database or calculated from the control chart. The program version described in this paper was written entirely in Turbo Pascal version 6.0 (Borland International, 1990) to permit a consistent user interface and rapid data exchange among different modules of the program.

A production trial was undertaken to verify that the knowledge-based system produced recommendations similar to the original expert whose knowledge was used to develop the program. Poinsettias were grown in 15 -cm-diameter $\left(2570-\mathrm{cm}^{3}\right)$ pots by Heins to height specifications of 35 to $40 \mathrm{~cm}$. Rooted cuttings were transplanted 20 Aug. 1991, were pinched 1 Sept., and were grown under natural day lengths with a target flower date of 25 Nov. One tall cultivar, Annette Hegg Dark Red, and two shorter cultivars, Supjibi and Celebrate 2, were grown as three separate crops of 30 plants each in the same greenhouse at Michigan State Univ. Twice each week during the production trial, the heights of three plants per crop were measured and entered onto a control chart. Growth retardant and temperature decisions of Heins were recorded and were implemented to control plant height. Heins tracked graphically crop height, but did not use the knowledge-based system to help make decisions. After the experiment was completed, data were entered into the knowledge-based system. Expert recommendations were compared with recommendations of the knowledgebased system (for reasons of brevity, only growth retardant recommendations are discussed.

The control charts for the three crops are shown in Fig. 3. All of the crops finished within the target window, although they were shorter than the reference value. The 'Annette Hegg Dark Red' crop (Fig. 3A) was above the window until 2 Ott., and five growth retardant applications (chlormequat applied as a foliar spray at $1500 \mathrm{ppm}, 5 \mathrm{ml} /$ plant) were made by Heins to reduce the rate of elongation. Heins was prepared to drop below the target window during midOctober with the expectation that the crop would grow back into the window by flowering date. This strategy was chosen because during the previ- ous season rapid stem elongation was observed in mid-October in response to canopy closure as the crop matured. No growth retardants were applied to the remaining two crops. The 'Celebrate 2 ' crop (Fig. 3B ) was below the target window for most of the production season, whereas 'Supjibi' (Fig. 3C) tended to remain within the window. All crops finished within the lower range of the final height specifications.

The knowledge-based system generally provided similar recommendations to those of Heins. CIs for each crop are presented in the lower part of Fig. 3 a-c. Looking up the CI in the action table (Table 1 ) for a given growth stage shows the growth retardants recommended by the knowledge-based system. Similar to Heins, five growth retardants were recommended by the knowledge-based system for the 'Annette Hegg Dark Red' crop, and no growth retardants were recommended for the remaining two crops. The knowledge-based system recommended an application on 21 Sept. to the 'Annette Hegg Dark Red' crop that was not applied by Heins and did not recommend a growth retardant on 6 Oct. because the crop was within the target window. In addition, the knowledge-based system recommended four low-rate applications (800 ppm chlormequat) and one medium-rate application (1500 ppm ), whereas Heins applied only medium-rate applications.

The knowledge-based system therefore did not react as strongly as Heins to deviations above the curve for 'Annette Hegg Dark Red'. Heins' recommendation to apply a growth retardant while the crop was within the target window indicated the target curve did not represent his control-strategy accurately. Following this production trial and analysis of graphs from betatest users, we are testing alternative reference curves for tall-growing cultivars such as 'Annette Hegg Dark Red' that attempt to reduce plant height early in the season compared with the standard curve. An initial arbitrary modification to the Richards function (Eq. [3]), setting the $H_{0}$ ) parameter to 0.004 , resulted in a curve that may be more appropriate for tall-growing cultivars (Fig. 4). Using the modified function as the reference curve, the knowledgebased-system recommendations more closely mimicked Heins' for 'Annette Hegg Dark Red'. The modified curve is viewed as a prototype, and research into 
(A)

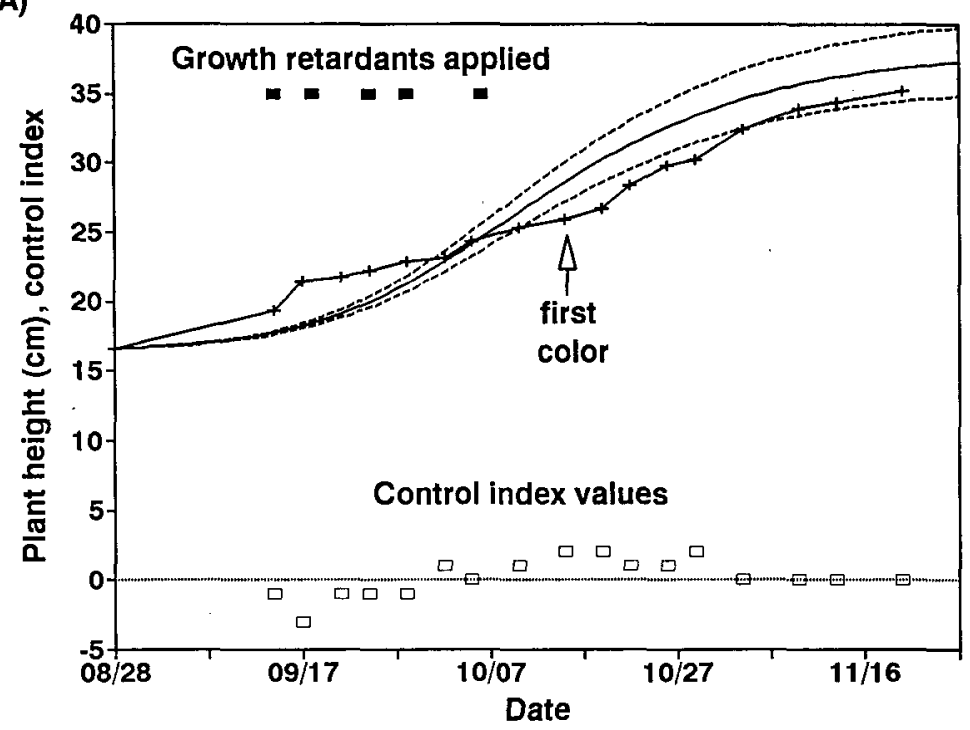

(B)

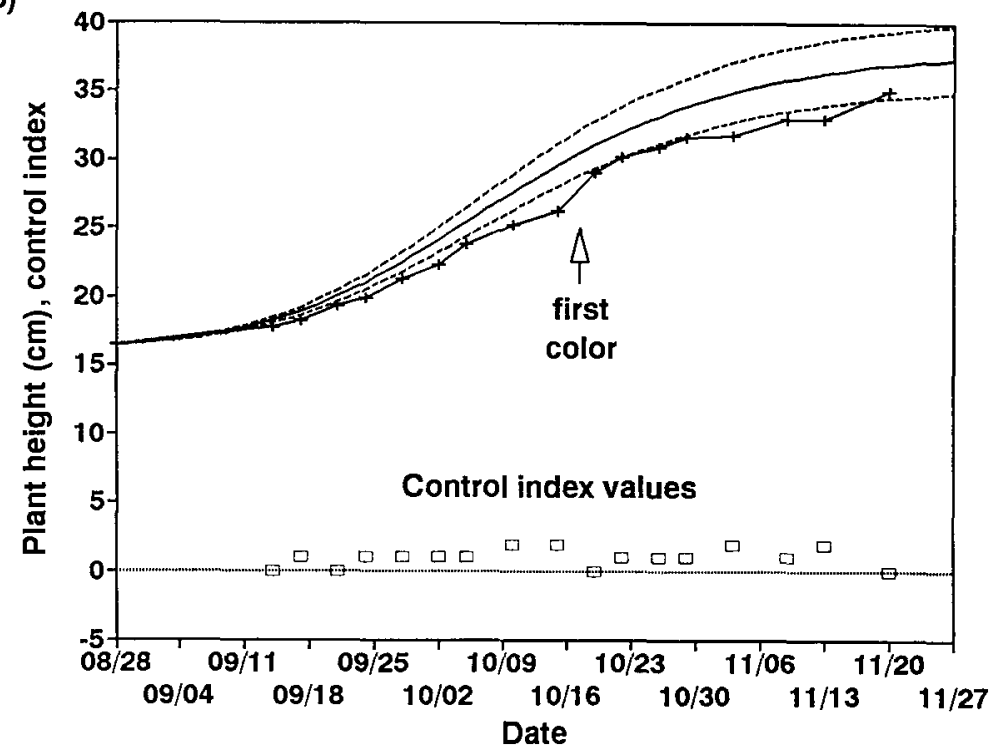

(C)

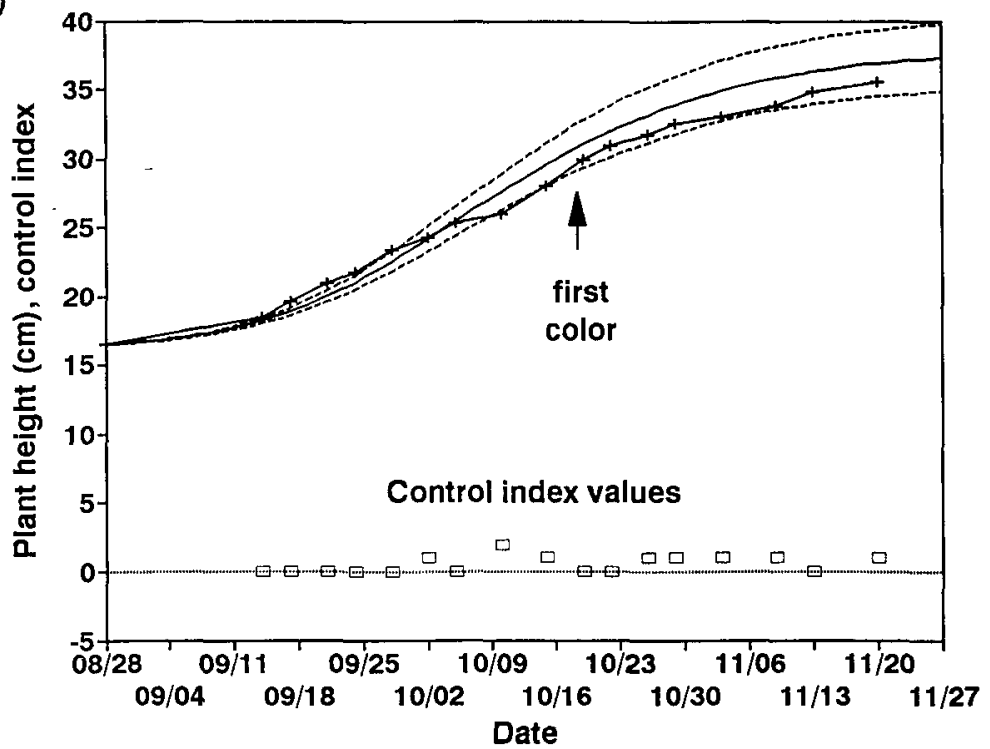

Fig. 3. Graphical height control charts from a production trial at Michigan State Univ. with three cultivars: (A) Annette Hege Dark Red, (B) Celebrate 2, (C) Supjibi. (+) Plant height, (solid box) actual growth retardants applied by Heins (1500 ppm chlormequat foliar sprays), (open box) CI values. appropriate reference curves is ongoing.

\section{Conclusion}

In summary, process control theory provides a powerful tool for production of greenhouse crops. Real-time greenhouse control problems have several features that lend themselves to computerization (Jones, 1989): a well-defined and narrow problem domain, inputs and outputs that can be defined completely and precisely, system goals are explicit, and success is tangible. A process control approach has been applied successfully to height control of greenhouse potted plants, a problem for which measurements can be taken cheaply and frequently, elongation responses to temperature and growth retardants are well-quantified, and computers already are widely used in the industry. The Greenhouse CARE System has been well-received by users and generally provides feasible guidelines and management recommendations.

\section{Future work}

Further validation of the poinsettia application is necessary. Experiments are underway in a research environment where the program is being used in the role of a decision-maker to grow a crop solely by knowledge-based system recommendations. At present, the program takes a narrow view of height control and makes important assumptions, especially with respect to plant health and the lack of other production problems. For example, if a nutrition problem occurred, the program would recommend temperatures that increase height but would not deal with the root causes of why the crop was elongating slowly. A further current limitation in the knowledge-based system is that historical data are used to make recommendations without considering future projected elongation. In contrast, Heins grower considered expected weather, changes in plant density, and the residual activity of growth retardant applications when making recommendations. A simulation model is being developed to incorporate into the knowledge-based system, so that the CI can be calculated based on projected and historical stem elongation.

The process control approach also could be applied to other crops, other time frames (e.g., by measuring frequency in months rather than days), and other decision areas (e.g., soil fertil- 


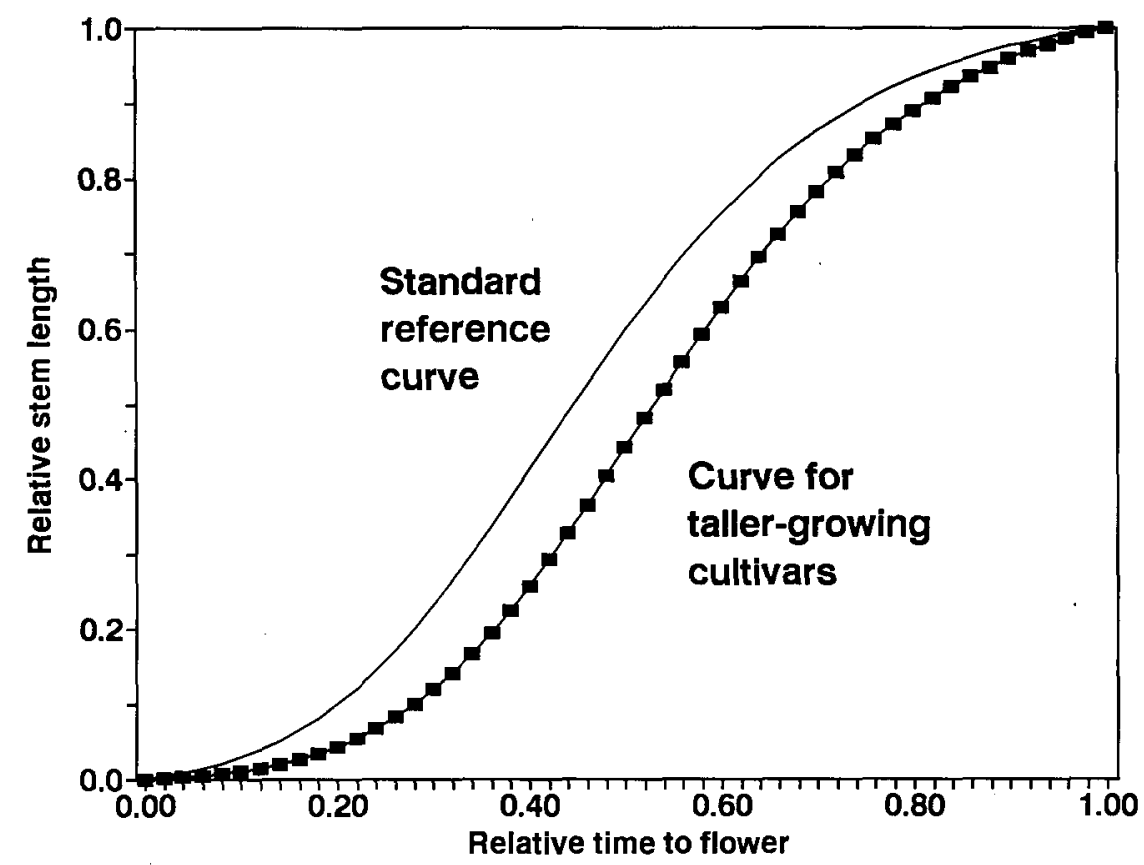

Fig. 4. Modified graphical control curve for taller-growing cultivars.

ity or pest and disease management). Packaging research information as graphical tools and decision-support systems provides a convenient delivery tool for transferring technology to growers.

\section{Acknowledgments}

We gratefully acknowledge funding by University Outreach at Michigan State Univ. We also thank Niels Ehler of the Royal Veterinary and Agricultural Univ. at Copenhagen, Denmark, for his thoughtful discussions and input.

\section{Literature Cited}

Barrett, J. and T.A. Nell, 1993. Growth retardant practices to avoid effects on poinsettia bract size. Georgia Commercial Flower Growers Assn. Nwsl. July-August 1993:7-8.

Beck, H. W., P. Jones, and J. W. Jones. 1989. SOYBUG: An expert system for soybean insect pest management. Agr. Systems 30:269-286.

Berghage, RD. and R.D. Heim. 1991. Quantification of temperature effects on stem elongation in poinsettia. J. Amer. Soc. Hort. Sci. 116:14-18.

Borland International. 1990, Turbo Pascal version 6.0 user's guide. Borland Ind., Scotts Valley, Calif.

Carlson, W.H. and RD. Heins. 1990. Get the plant height you want with graphical tracking. GrowerTalks 53(9):62-68.

Cook, D.F., J.G. Massey, and C. McKinney, 1992. A knowledge-based approach to statistical process control, Computers Electronics Agr. 7:13-

Erwin, J.E., R.D. Heins, and M.G. Karlsson.
1989. Thermomorphogenesis in Lilium longiflorum J. Amer. Bot. 76(1):42-52.

Erwin, J.E. and R.D. Heins. 1990. Temperature effects on lily development rate and morphology from the visible bud stage until an thesis. J. Amer. Soc. Hort. Sci. 115:644-646.

Ewan, W.D. 1963. When and how to use cu-sum charts. Technometrics 5(1): 1-22.

Fynn, R. P., W.L. Roller, and H.M. Keener. 1989. A decision model for nutrition management in controlled environment agriculture, Agr. Systems 31:35-53.

Grossman, K. 1992. Plant growth retardants: theirmode of action and benefit for physiological research, p, 788-797. In: C.M. Karssen, L.C. van Loon, and D. Vreugdenhil (eds. ). Progress in plant growth regulation. Kluwer, Netherlands.

Heim, RD. and J.E, Erwin. 1990. Understanding and applying DIF. Greenhouse Grower 8(2):73-78.

Jones, P., B.K. Jacobson, and J. W. Jones. 1988. Applying expert systems concepts to real-time greenhouse controls. Acts Hort. 230:201-208.

Jones, P. 1989. Agricultural applications of expert systems concepts. Agr. Systems 31:3-18,

Miller, R.E. 1985. Time series analysis. Chem. Eng. 10 June 1985:85-90.

Murrill, P. W. 1981, Fundamentals of process control theory. Instrument Sot. Amer., Research Triangle Park, N.C.

Nelson, L.S. 1985. Interpreting Shewart $\times$ control charts. J. of Qual. Technol. 17: 114-1 16.

Quinn-Curtis. 1990. PID control. III. Realtime science and engineering tools for Turbo Pascal. Quinn-Curtis, Needham, Mass.

Richards, F.J. 1959. A flexible growth function for experimental use. J. Expt. Bet. 10:290-300.

Stock, M., 1987. Al and expert systems: An overview. AI Applications 1(1):9-17. 